\title{
Modeling of the Elastic Plates of Non-Base Configurations for the Cams of Automatic Half-Hose Machines
}

\author{
Leonid Berezin ${ }^{1 *}$, Kyrylo Savchenko ${ }^{2}$, Mykola Rubanka', Oleh Polishchuk ${ }^{3}$, \\ Olena Oliinyk ${ }^{4}$, Alla Rubanka ${ }^{1}$
}

1 Kyiv National University of Technologies and Design, 2 Nemyrovycha-Danchenka Street, 01011 Kyiv, Ukraine

2 G.S. Pisarenko Institute for Problems of Strength of the National Academy of Sciences of Ukraine, 2 Timiryazevs'ka str., 01014 Kyiv, Ukraine

3 Khmelnytskyi National University, 11, Instytuts'ka str., Khmelnytskyi, 29016, Ukraine

${ }^{4}$ National Technical University of Ukraine "Igor Sikorsky Kyiv Polytechnic Institute", 37, Prosp. Peremohy, 03056 Kyiv, Ukraine

* Corresponding author's email: Inb07@ukr.net

\begin{abstract}
The purpose of the work was analytical research and computer modeling of the influence of shape and size of console beams of elastic plates in non-base configurations for the cam of the automatic half-hose machine under the conditions of flexibility, strength, and minimization of sizes. The scientific novelty of the work lies in the further development of the theory and methodology of designing the elements of knitting systems of the automatic half-hose machines based on regimes of loading, limitations in strength and dimensions, as well as requirements of the technological process. In order to increase the flexibility of the elastic plate, the symmetrical introduction of two console beams of trapezoidal shape was proposed. The influence exerted by the coefficient of the shape of console beams and their lengths on the magnitudes of deflections and stresses was analyzed, which allows making grounded and flexible decisions regarding the dimensions of the root and the end sections of the beams at the preliminary stage of design. The mathematical support was presented mainly in an explicit form, which simplified the analysis of the influence of controlled dimensions of the elastic plates on their flexibility and strength, as well as contributes to the comprehensive approach to the development of cams of different constructions with elastic plates and allows improving the quality and efficiency of design solutions of cams. The beam bending theory and the finite element method based on Code_Aster shared software were used. The model of the plate was represented by an ordered grid of finite nodal elements of the same size, without the use of elongated and flat elements. According to the results of simulation experiments, the distributions of deformations and stresses on the surface of the elastic plate of the cam were obtained, depending on its shape and size, which confirmed the validity of calculated recommendations.
\end{abstract}

Keywords: elastic plate of the cam, strength, flexibility, Finite Element Method, Code_Aster.

\section{INTRODUCTION}

The automatic half-hose machines belong to circular knitting machines with a small diameter of needle cylinder up to 4 ". The technological trajectories of the needles are ensured by the rotation of the cylinder and the interaction with the cams called knitting cams. A set of cams around the cylinder includes at least a raising cam, a stitch cam, and an upthrow cam, which form the cams of the knitting system in the knitting mechanism. The change in the direction of movement of the needles relative to the cylinder is determined by the cams, which is accompanied by repeated-variable loadings and leads to the fatigue failure of the needle hooks [1-3].

According to the results obtained from the dynamic analysis of the interaction in the 
needle-cam-cylinder slot system $[1,4,5]$, it is obvious that the angle of slope $\alpha$ of the working surface of the cam and the rigidity $C$ of the needle when interacting with the cam, have the main influence on minimization of the impact force $F$. The reduction of $\alpha$ for the entire surface of the cam is critical in relation to the length of the knitting system cams; that is why in practice, the cams with curved surfaces are preferred. The general principles concerning the construction of nonlinear profiles of cams in accordance with the technological and dynamic requirements are well presented in the literature, starting from theoretical research [6-8] to the automated design of high-order polynomials and production using the CAD/CAM technologies [9-11]. The expediency of using profiled sloping raising cams and stitch cams in the automatic half-hose machines is limited to some extent due to the periodic change of the point of interaction between the needle heel with the surface of the cam and is generally unacceptable for the horizontal upthrow cams with the vertical application of force. Therefore, regarding the automatic half-hose machines, a promising direction of minimizing the impact force $F$ is to increase the flexibility in the needle-cam pair, especially using the cams with elastic elements $[12,13]$.

In the paper [14], the elastic element of the cam with non-base configuration - the plate of a complex shape (Fig.1) that has a double console and transverse beam deformations - was researched. Due to the results of modeling at the maximum force $F=14 \mathrm{~N}$ [1], limiting the dimensions of the plate $(L=27 \mathrm{~mm}, H=10.9 \mathrm{~mm}, h$ $=0.7 \mathrm{~mm}$ ) and the maximum permissible deflection $\mathrm{y}_{\max } \leq 0.22 \mathrm{~mm}$, using the SH15 steel as the material, the controlled widths of the console beam $\mathrm{B}=3.8 \mathrm{~mm}$ and the transverse beam $b=3$ $\mathrm{mm}$ were obtained, considering the requirements of flexibility and strength. From the analysis of the screenshot (Fig. 2) showing the distribution of equivalent stresses on the surface of the elastic plate, it is obvious that it is expedient to replace the console rectangular beams with constant transverse dimensions along their length by

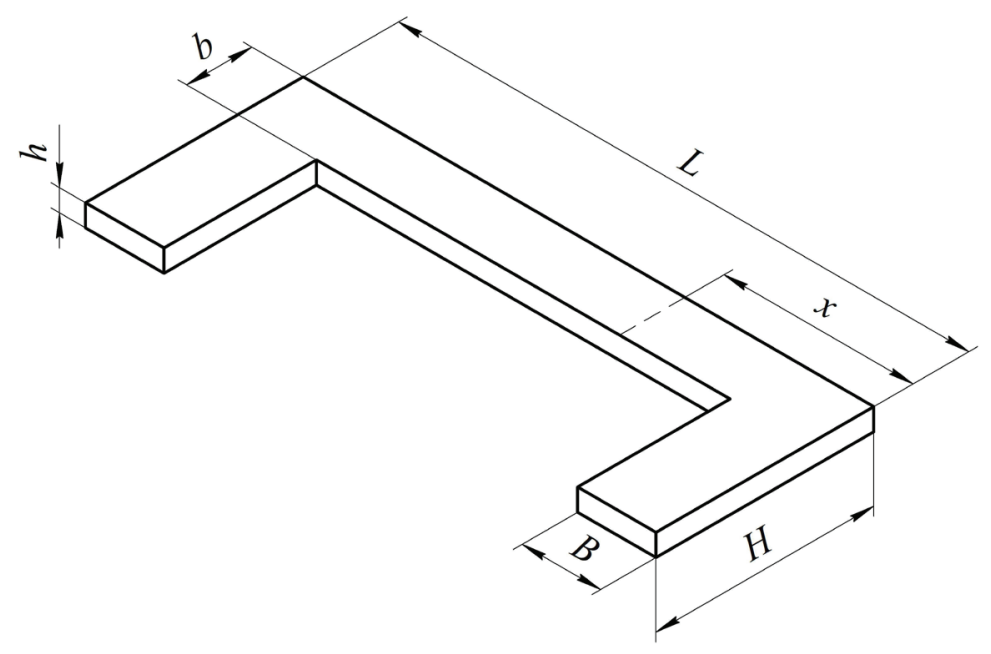

Fig. 1. The design model of the elastic plate of the cam: $x$ - the coordinate of the point of application of force

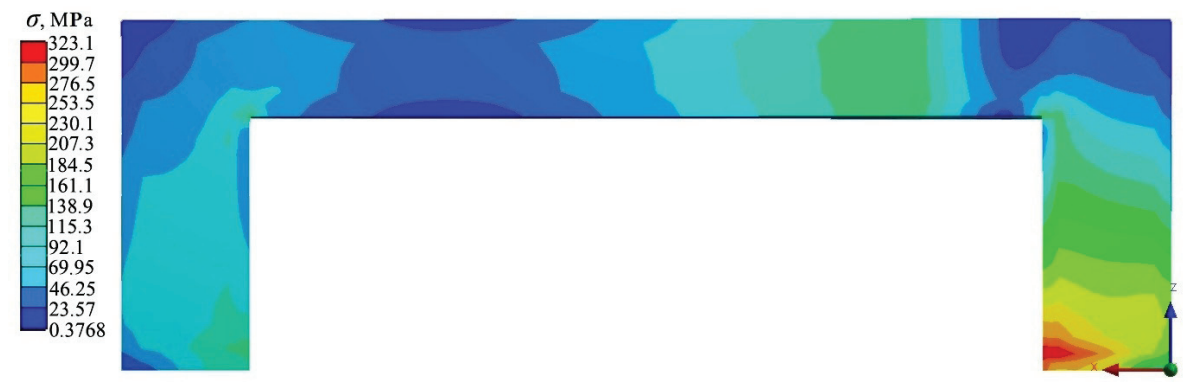

Fig. 2. The distribution of equivalent stresses on the surface of the rectangular elastic plate, considering that $\mathrm{B}=3.8 \mathrm{~mm}, \mathrm{H}=10.9 \mathrm{~mm}$ 
beams of trapezoidal shape [15-17]. This will increase the deflections of the plates at $H=$ const in general or decrease $\mathrm{H}$ at a constant deflection.

\section{RESEARCH METHODOLOGY}

The purposes of this article included conducting the analytical research and computer modeling related to the influence of shape and size of console beams of elastic plates in non-base configurations for the cam of automatic half-hose machine under the flexibility and strength conditions, minimizing the console sizes.

Let us consider the right console. The value $F_{1}=9.8 \mathrm{~N}$ is determined by the decomposition of the force $F$ into a system of two parallel forces that do not form a pair [18]. Symbols $v_{1}(0)$ and $v_{2}(0)$ denote the deflections of the conditionally free ends of the rectangular and the trapezoidal console beams as a result of the applied force $F_{1}$. As the length of the console is much greater than its other dimensions, it is sufficient to use conventional beam theory, taking into account the normal stresses from bending and neglecting the tangential shearing stress between the layers of the beam [19]. Considering [16], we have:

$$
v_{1}(0)=\frac{4 F_{1} l^{3}}{E a(1) h^{3}}
$$

where: $l=H-0.8 b=8.5 \mathrm{~mm}-$ length of the console beam;

$E=2.11 \cdot 10^{\circ} \mathrm{MPa}$-elastic modulus of the SH15 steel [20, 21];

$a(1)=B$ - width of the beam in the root section (trivially determined by the condition of bending strength).

Inserting the initial data in (1), we have a calculated value $v_{1}(0)=0.0875 \mathrm{~mm}$, which is within the range $\{0.0744 ; 0.099\} \mathrm{mm}$, according to the screenshots of deflections in [14].

The "perfect" consoles mean the consoles with a constant bending resistance, the condition for equal bending strength of which is presented in [22]:

$$
\frac{6 F z}{a(z)}=\frac{6 F l}{a(1) h^{2}}
$$

where from:

$$
a(z)=\frac{a(1)}{l} z
$$

Thus, the "perfect" console looks like a triangle, where $a(z)$ - the width of the cross-section of trapezoidal console depending on the distance $z$ from the top of the triangle. However, the console of such a shape cannot be structurally attached to the cross beam. Moreover, it is necessary to check the console for a cut in a dangerous section with a minimum width [16]:

$$
\tau_{\max }=\frac{3}{2} \frac{Q_{\max }}{h a_{\min }(z)} \leq[\tau]
$$

where: $Q_{\max }-$ shearing force $\left(Q_{\max }=F_{1}\right)$;

$[\tau]$ - permissible tangential stress in cut (considering the recommendations [20], we have $[\tau]=0.6[\sigma]=199.8 \mathrm{MPa}$ ).

After calculations, the minimum permissible width of the console at the point of attachment to the cross beam is $a_{\text {min }}(z)=0.11 \mathrm{~mm}$.

As the console is attached to the cross beam with a width $b=3 \mathrm{~mm}$, and considering the condition (3), we obtain $a(z=b)=\frac{a(1)}{l} b=\frac{3.8}{8.5} 3=1.34 \mathrm{~mm}$, which is much higher than the minimum permissible value. For design reasons, we choose $a_{\min }(0)=2.3 \mathrm{~mm}$ to reduce the concentrator of stress. The connection between the deflections $v_{2}(0)=v_{1}(0) \theta$ was analyzed in [23] and was determined by the trapezoidal shape coefficient $k_{i}=\frac{a_{i}(0)}{a(1)}$ (for rectangular console $\kappa=1$, as $a_{i}(x)=a(0)=a(1)=$ const $)$.

There is tabular information on the dependency of $\theta_{i}$ on $\kappa_{i}$ but the formulas are more convenient, in particular of the following type

$$
\theta_{i}=\frac{3}{2+\kappa_{i}} \geq 1
$$

Considering that $a(1)=3.8 \mathrm{~mm}$ and calculating that $a(0)=2.3 \mathrm{~mm}$, we have an increase in the deflection of the console beam of equal strength compared to the rectangular one for $\theta=\frac{3}{2+\frac{2.3}{3.8}}=1.152$ times, that is $v_{2}=0.0875 \cdot 1.152=0.101 \mathrm{~mm}$.

The finite element method was chosen as the mathematical basis for the computer modeling of the elastic plate of the cam [24], the example regarding the design of the cam is given in [25]. An ordered grid of finite 8-node elements of the same size, without the use of elongated and flat 
elements, was the model for the plate. The construction of the parametric model and the processing of the obtained data were performed in the Code_Aster software environment, which is compatible with the existing open Salome preprocessor $[26,27]$ and the graphical interface of the user. In addition to the open-access benefit, the use of Code_Aster-based computer modeling has a non-competitive priority over the long-term procedures of field research.

\section{RESULTS}

The modeling of the elastic plate was performed, considering the deflection magnitude $v_{2}(0)$ with a change $a_{i}(0)$ within the 2.3 and $3.8 \mathrm{~mm}$ with an interval of $0.5 \mathrm{~mm}$ at constant values $l, h$ and $F_{1}$. Figure 3 and 4 show the distribution of deflections and normal stresses at the points of the plate for the case when $a_{i}(0)=2.3 \mathrm{~mm}$.

In Figure 2, the fulfillment of the condition of strength $\sigma_{\text {max }}=323.1 \mathrm{MPa}<[\sigma]=333 \mathrm{MPa}$ is obvious, in the Figure 4 - the fulfillment of the condition of equal strength along the console is obvious as well (the local deviations occur in the fixing of the console and near the stress concentrator). In the case of designing, considering the given flexibility, it is advisable to use the following formula:

$$
C=\frac{v_{i}(0)}{F_{1}}=\frac{4 \theta}{E a(1)}\left(\frac{l}{h}\right)^{3}
$$

As an example, at $a(0)=2.3 \mathrm{~mm}$ and $a(1)=3.8 \mathrm{~mm}$, we have a flexibility $\mathrm{C}=1.029 \cdot 10^{-5} \mathrm{~N} / \mathrm{m}$. Then in the calculations of the impact force, the required rigidity is $K=\frac{1}{C}=0.9718 \cdot 10^{5} \mathrm{~N} / \mathrm{m}$.

Let us consider the impact of $a_{i}(0)$ on the length of the beam under the condition of a given deflection $v_{2}(0)=$ const . Where as

$$
v_{2}(0)=v_{1}(0) \theta=\frac{4 F_{1}}{E a(1)}\left(\frac{l}{h}\right)^{3} \theta
$$

then at the given $v_{2}(0)=0.0875 \mathrm{~mm}$, after the insert and simplification, we have:

$l_{i}=\sqrt[3]{\frac{E a(1) h^{3} \cdot v_{2}(0)}{4 F_{1} \cdot \theta_{i}}}=8.50 \sqrt[3]{\frac{2+\frac{a_{i}(0)}{a(1)}}{3}}, \mathrm{~mm}$

Then $H_{i}=l_{i}+0.2 b$. For the rectangular console at $a(0)=3.8 \mathrm{~mm}$ and $\kappa=1$ we have $H=8.5+0.8 \cdot 3=10.9 \mathrm{~mm}$.

Figure 5 shows the impact of the change $a_{i}(0)$ on the length of the beam $l$ at a constant deflection $v_{2}(0)=0.1732 \mathrm{~mm}$.

Thus, at the value of $a(0)=2.3 \mathrm{~mm}$ and the corresponding shape coefficient $k_{\min }=0.605$, the relative change in the deflection and the length of the console in relation to the rectangular one at $a(0)=3.8 \mathrm{~mm}$ are $\varepsilon_{v(0)}=15.2 \%$ and $\varepsilon_{l}=9.6 \%$, respectively.

In addition, considering the technological necessity for a reverse movement of the needle wheels along the cam, we accept the left console with the sizes similar to the right one and calculate its deflection at the force $F_{2}=F-F_{1}=4.2 \mathrm{~N}$. Since, according to the formula (1), the deflection of the console is proportional to the force, for the left console and the two console beams of the cam plate we have $\frac{4.2}{9.8} v_{2}(0)$ and $1 \frac{4.2}{9.8} v_{2}(0)$,
respectively.

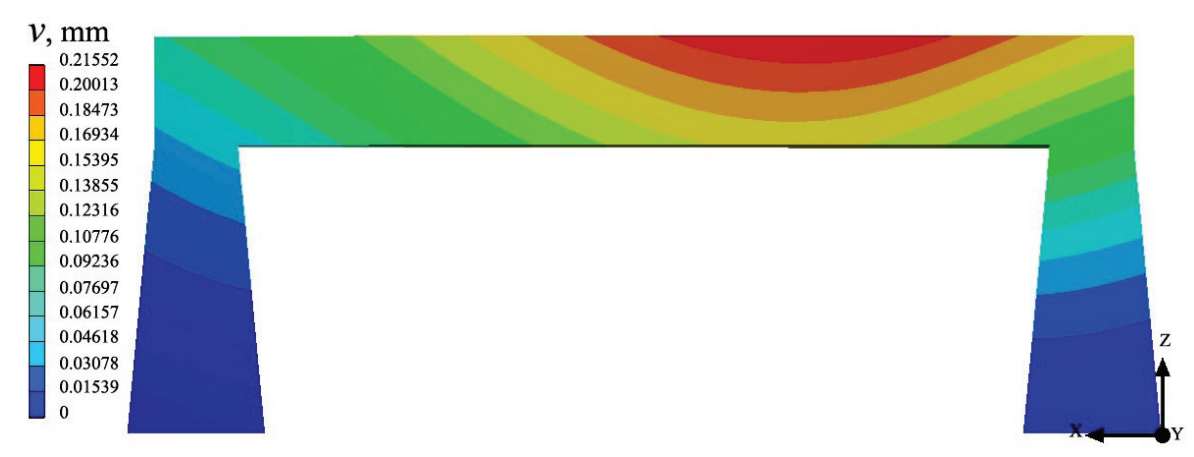

Fig. 3. The distribution of deflections of the elastic plate with the consoles of trapezoidal shape at $a_{i}(0)=2.3 \mathrm{~mm}$ and $H=10.9 \mathrm{~mm}$ 


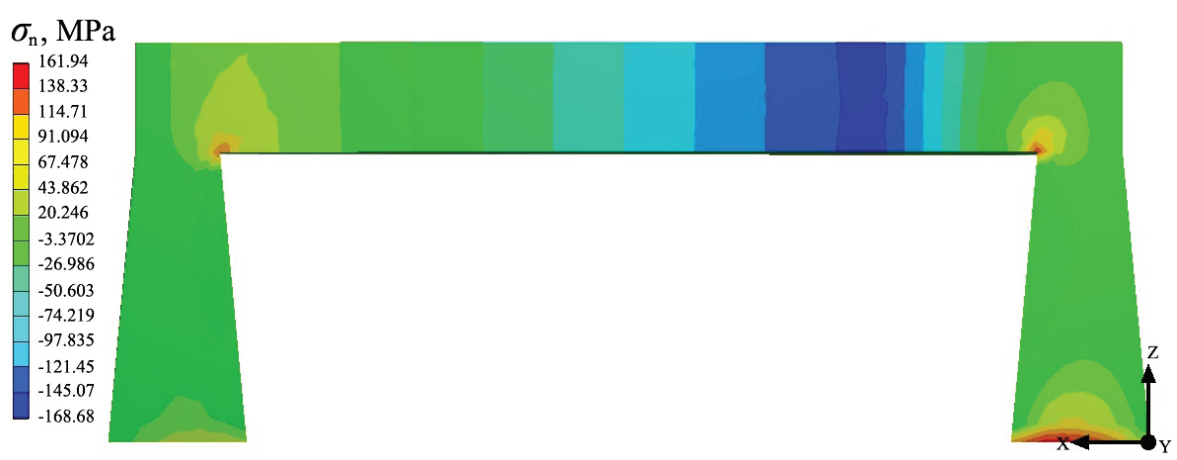

Fig. 4. The distribution of normal stresses on the surface of the elastic plate with the consoles of trapezoidal shape at $a_{i}(0)=2.3 \mathrm{~mm}$ and $H=10.9 \mathrm{~mm}$

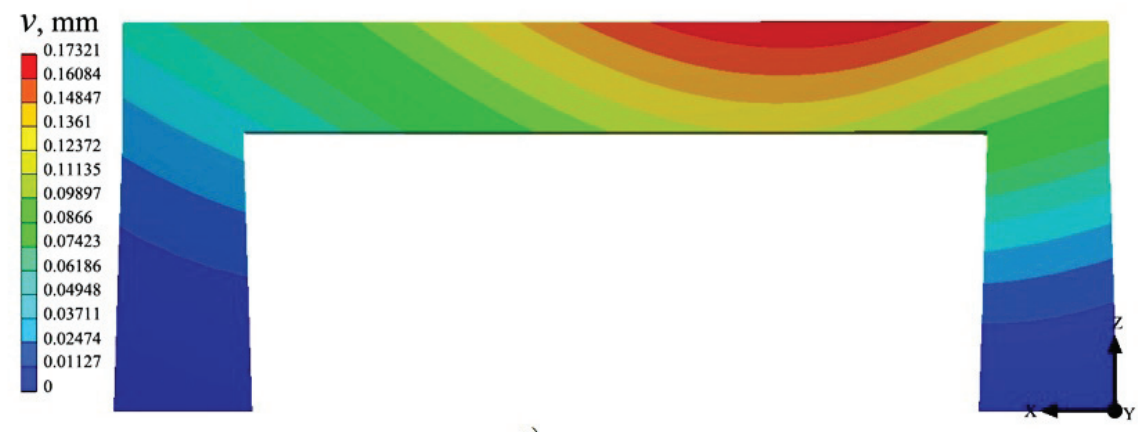

a)

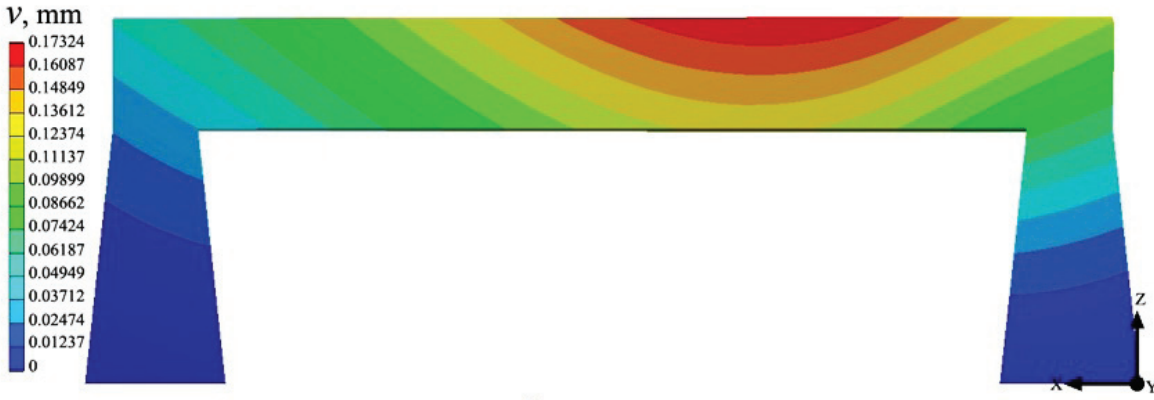

b)

Fig. 5. The distributions of deflections of the elastic plate on change of the length of the consoles and the constancy of the maximum deflection with the consoles of trapezoidal shape:

a) at $a(0)=3.3 \mathrm{~mm}$ we have $H=10.6 \mathrm{~mm}$; b) at $a(0)=2.3 \mathrm{~mm}$ we have $H=9.87 \mathrm{~mm}$

The diagrams $v_{i}=f\left[a_{i}(0)\right]$ and $l_{i}=f\left[a_{i}(0)\right]$, based on calculations and computer modeling, are presented in Figures 6 and 7.

\section{CONCLUSIONS}

The possibility and the expediency of using the computer modeling for the elastic element of non-base configuration of the cam of automatic half-hose machine with the application of the Salome Meca open-source software, based on Code Aster, and the finite element method were presented.
The comparative analysis of the results of calculations and the results of computer modeling of the elastic plates confirmed their sufficient degree of accuracy. Moreover, the formulas (1-7) are convenient for use and presentation in an explicit form, which simplifies the analysis of the influence of the controlled size of the elastic plate on its deflection. Obviously, these provisions should be used mainly at the stage of preliminary designing.

The methodology and mathematical support, which allow modeling the configuration of the elastic plate of the cam of the automatic half-hose 


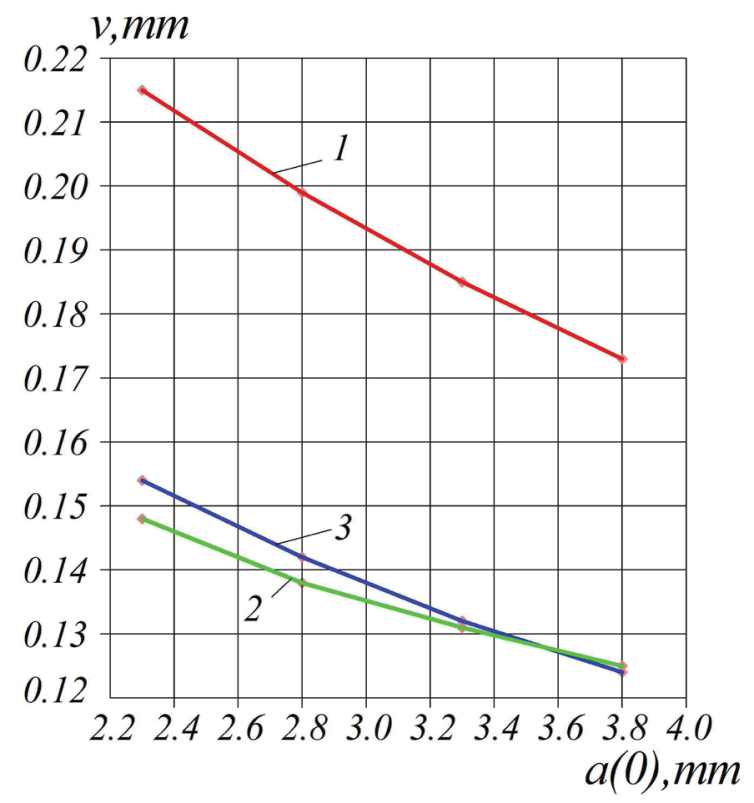

Fig. 6. The diagrams of deflection $v_{i}$ depending on the width $a_{i}(0)$ of the console beams: 1 - elastic plate in general; 2 - two console beams according to the results of calculations; 3 - two console beams according to the results of computer modeling

machine under the conditions of flexibility and minimization of sizes of its console components were offered.

In the future, we consider it appropriate to continue the research on the minimization of cam sizes in the transition from the traditional methods of analysis that use the normalized safety factors to the analysis for fatigue strength in the probabilistic figuration with a given level of reliability.

\section{REFERENCES}

1. Berezin L.M. Evaluation of the durability and reliability of knitting mechanisms of automatic half-hose machines. Kyiv: KNUTD, 2012, 191.

2. Gaidamaka V.K., Krasovskyi A.Y., Kramarenko I.V. The causes and the nature of destruction of the needles of knitting machines. The problems of strength, 1983, 3, 68-71.

3. Neumann H. Betrachtung von nadelstớrungen ihre entstehung und auswirkungen. Melliand Textilberichte, 1975, 5, 372-376.

4. Duru S.C., Candan C., Mugan A. Effect of yarn, machine and knitting process parameters on the dynamics of the circular knitting needle. Textile Research Journal, 2015, 85(6), 568-589.

5. Jurgens R., Pestel K. Er fassung der dynamischen belstung des nadelfasses beim strickprozess. Textiltecnik, 1982, 5, 287-290.

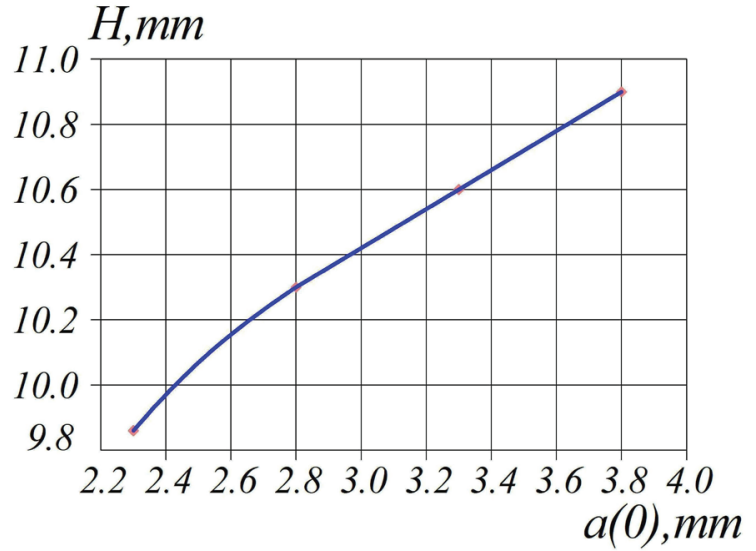

Fig. 7. The diagrams of influence of the width of the console beams $a_{i}(0)$ on their length $H_{i}$ at a given constant deflection of the elastic plate

6. Lau TWY and Knapton JF. The design and dynamics of nonlinear cams for use in high speed weft knitting machines Part II: The analysis of knitting yarn tensions with non-linear cams theoretical dynamics of non-linear cams. Journal Textil Institute, 1978, 69, 169-175.

7. Budulan C., Andriesan L. Systemes non-lineares de cames pour des machines a tricoter circulaires interlocr a 96 systemes. Buletinul Institutului Politehnic din Iaşi, 1984, 1, 63-72.

8. Oldham K, Burns ND and Simms GJ. Non-linear cams for weft-knitting machines. Journal Textil Institute, 1985, 1, 30-37.

9. Jian-qiao J., Xiao-jian M. An analysis on the dynamic characteristics of the cam of flat knitting machine and its optimised design. Knitting Industries, 2006-03.

10. Song G., Li Y., Wu J. A study on the optimum design of non-linear cam profiles in weft-knitting machines. Journal of the Textile Institute, 2004, 95, 171-182.

11. Simms G.J., Oldham K., Burns N.D. Application of CAD to knitting machine design. Journal Computer-Aided Design, 1983, 15(2), 89-97.

12. Pipa B.F., Pleshko S.A. Improvement of working bodies of mechanisms of knitting circular knitting machines. Kyiv: KNUTD, 2012, 471.

13. Berezin L.M. Calculation of the flexibility plate of the cam according to the criterial of rigidity and longevity. Bulletin of the Kyiv National University of Technologies and Design, 2016, 3, 68-73.

14. Berezin L.M., Savchenko K.V. Modelling of a flexible grinder of a complex shape form on the criteria of deformation and strength. Herald of Khmelnytskyi national university, 2019, 6, 24-27.

15. Suriyaninov N.G., Vlazneva A.Yu. Calculation of leaf springs of variable stiffness. Proceedings of the Odessa National Polytechnic University, 2009, $1,19-23$. 
16. Kochetov V.T., Kochetov M.V., Pavlenko A.D. Strength of materials. Saint Petersburg: BKhV-Peterburg, 2004, 544.

17. Nyashin Yu.I., Osipenko M.A., Gitman M.B. Equally stressed leaf springs. Vestnik of Nosov Magnitogorsk State Technical University, 2014, 4, 22-26.

18. Pavlovskyi M.A. Theoretical mechanics. Kyiv: Tekhnika, 2002, 510.

19. Rabotnov Yu.N. Mechanics of a deformable solid. Moscow: Nauka, 1988, 712.

20. Troshchenko V.T., Sosnovskiy L.A. Fatigue Strength of Metals and Alloys. Kyiv: Naukova Dumka, 1987, 808.

21. GOST 801-78. Stal' podshipnikovaya. Tekhnicheskie usloviya. [State Standart 801-78. Bearing steel. Specifications]. Moscow, Standartinform Publ., 1978, 43 p.

22. Polilov A.N., Tatus N.A., Tian Xiaoyong. Shaped and branched analogs of triangle multi-leaf spring.
PNRPU Mechanics Bulletin, 2008, 4, 209-222.

23. Berezin L.M. To the calculation of the geometric parameters of flexible facets of cams. Bulletin of the Kyiv National University of Technologies and Design, 2019, 5, 9-16.

24. Suriyaninov N.G., Pavlenko I.V. Calculation of plates by numerical-analytical method of boundary elements. LAB LAMBERT Academic Publishing, Germany, 2013, 178.

25. Semnani D., Matin K., Sheikhzadeh M., Latifi M. Automation of stitch length cams in high speed flat weft knitting machines: Online control system and numerical modeling method. International Journal of Applied Engineering Research, 2008, 3(6), 763-772.

26. Aubry J.P. Beginning with Code aster. Paris, France, 2013, 329.

27. Code_Aster, https://www.code-aster.org/V2/spip. ph-p?rubrique2 (available at 20.09.2020). 